\title{
Impact of type of the roof rocks on location and range of endogenous fires particular hazard zone by in goaf with caving
}

\author{
Magdalena Tutak ${ }^{1, *}$, and Jarosław Brodny ${ }^{2}$ \\ ${ }^{1}$ Silesian University of Technology, 2 Akademicka St., 44-100 Gliwice, Poland \\ ${ }^{2}$ Silesian University of Technology, 26-28 Roosevelta St., 41-800 Zabrze, Poland
}

\begin{abstract}
Hazard of endogenous fires is one of the basic and common presented occupational safety hazards in coal mine in Poland and in the world. This hazard means possibility of coal self-ignition as the result of its self-heating process in mining heading or its surrounding. In underground coal-mining during ventilating of operating longwalls takes place migration of parts of airflow to goaf with caving. In a case when in these goaf a coal susceptible to self-ignition occurs, then the airflow through these goaf may influence on formation of favorable conditions for coal oxidation and subsequently to its self-heating and self-ignition. Endogenous fire formed in such conditions can pose a serious hazards for the crew and for continuity of operation of mining plant. From the practical point of view a very significant meaning has determination of the zone in the goaf with caving, in which necessary conditions for occurence of endogenous fire are fulfilled. In the real conditions determination of such a zone is practically impossible. The main aim of the analysis was to determine the impact of type of the roof rocks forming the goaf on the location and range of endogenous fires particular hazard zone by in these goaf. For determined mining-geological conditions, the critical value of velocity of airflow and oxygen concentration in goaf, conditioning initiation of coal oxidation process were determined.
\end{abstract}

\section{Introduction}

In mined seams of the Upper Silesian Coal Basin there are five basic lithological types of rocks: sandstones, mudstones, coal shales and hard coal with different type of strength properties.

Up to now strength properties of rocks surrounding the mining heading were considered the most often in the aspect of their influence on the maintenance of the stability of mining headings and yielding capacity for forming goaf with caving filling the space after mined usable mineral.

Practice shows that this influence should be considered also in the aspect of formation of ventilation hazards occurring in the underground mining headings, including the goafs of

\footnotetext{
Corresponding author: magdalena.tutak@polsl.pl
} 
longwalls. One of the ventilation hazards commonly present in goafs with caving is hazard of endogenous fires.

Goaf is a space in mined seam rock debris, filled with roof rocks, after the transition of mining front. This filling takes place as a result of spontaneous detachment of these rocks from the rock mass. Degree of filling of the selected surface depends on many factors, to which among the others one can include height from which rock block are falling down (thickness of the layer being exploited or thickness of the seam), type of the roof rocks and their strength properties, as well as the distance from the front longwall and depth of mining exploitation carried out. One of the most important factors deciding about the degree of filling of mined area is a type of roof rock forming goaf with caving and their stratification resistance. This resistance decides about their tendency to transition into caving state and about the permeability of caving debris [1-3]. Robust and compact roof rocks make the packing of cracked rock blocks looser and make them harder to transit into fall state, and weak and brittle rocks transit more easily into fall state, thus the fall is characterized by higher sealing and lower permeability. Independently of goaf with caving being formed by robust and compact rocks or weak and fragile rocks, empty spaces, called gaps, are always presented in this debris. These gaps together with the rock blocks create porous medium through which flow of ventilated air and mining gases is possible.

Flow of gases through the goaf with caving is a result of migration into them a part of ventilation air stream flowing through the wall heading in the process of its ventilation. Amount of migrating stream depends on many factors among the others, also on a type of applied support in the dog and longwall headings. [4-10]. The air stream flowing into the goafs creates dangerous initialization of low temperature reaction of coal oxidation which can lead to self-ignition of remained coal in the goaf with caving. It also can cause the outflow of mining gases (for instance methane) to others headings.

Necessary conditions to initialize oxidation process of coal, besides its presence is a flow through the air goafs with determined velocity and proper oxygen concentration. Fulfilment of these conditions creates possibilities to initialize low temperature reaction of carbon oxidation during which heat is emitted, which is accumulated by coal and causes increase of its temperature. If this state is kept through appropriately long time, it may come to self-ignition of coal, that is occurrence of endogenous fire. The most important factor influencing on the process of heat accumulation is the velocity of air stream flowing through the goaf with caving of exploitation longwall. This velocity is dependent among the others on a type of roof rocks forming the goaf. Type of these rocks influences on the degree of sealing of goafs, which subsequently decides about their permeability.

Results of tests indicate that critical value of air stream, causing self-heating of coal is in the range from 0.0015 to $0.02 \mathrm{~m} / \mathrm{s}$ [9-14]. Laboratory tests of coal oxidation indicated that boundary value of oxygen concentration below which self-heating did not occur is equal to $8 \%$. [13-15]. Oxidation process occurs in area where above specified necessary conditions for its initiation are satisfied. This area can be defined as a particular hazardous zone of endogenous fires.

Therefore, it is reasonable to conduct studies in order to determine the range of this zone. Determination of this zone in underground conditions in practice is impossible to perform, because it is formed in inaccessible places, what precludes to carry out direct tests.

It is necessary to use also other, more safe methods to determine location of this zone. Such possibilities create modelling tests using the numerical methods of fluid mechanics.

These methods in recent years more and more often are used to analyse ventilation problems. They enable variant analyses of processes connected with ventilation of underground mine heading, and also in analyses of states of emergency [7-15]. In analyzed case, the Finite Volume Method for determination of location and range of endogenous 
fires particular hazard zone in goaf with caving was used. Analyses were performed taking into account a type of roof rocks forming caving, having significant impact on location and range of this zone. Real longwall heading was submitted to the tests, for which ventilation parameters of air and geological structure of surrounding rock mass were known. The aim of test was to determine location and range of endogenous fires particular hazard zone in goaf with caving treated as porous medium.

Obtained results clearly indicate rightness of application of fluid mechanics for analysis of ventilation phenomena in porous media. This method in connection with geologicalmining tests enables to determine the physical and chemical parameters of air and gases mixture in goafs. This subsequently enables to determine location and range of endogenous fires particular hazard zone. Based on these information, one can make with proper advance preventive actions in aim to limit its hazard.

\section{Division of the roofs due to the value of destratification resistance of roof rock}

The most significant property of roof rocks, due to formation of a caving zone in mined layer is stratification resistance is defined as the strength to loosening under the gravity force. The value of this resistance decides about the rock tendens to pass in a heap and about the permeability of forming goaf with caving in this process [1-3].

Stratification resistance of rocks is determined experimentally using downhole penetrometers or by an indirect method by disruption segments of vertical drilling of bore in the direction of the longitudinal axis of the opening. In a second case its value is calculated from dependence:

$$
R_{r r s}=0,8 \frac{F}{d^{2}}
$$

In a Table 1 there is presented division of roofs based on rock type littering over exploited seam. Additionally, also a value of stratification resistance and description of behavior of these roofs after selection of layer were given.

Table 1. Division of roofs [3].

\begin{tabular}{|c|c|c|}
\hline $\begin{array}{c}\text { Resistance } \\
\text { of roof } \\
\text { rock, } \\
\mathbf{R}_{\mathbf{r r s}}, \mathbf{M P a}\end{array}$ & Description of roof & Example of rock \\
\hline $0-0.5$ & roof falling immediately after unveiling & clay and sandy slates, \\
\hline $0.5-1.5$ & falling roof and weakly self-supporting & clay and sandy slates, coals \\
\hline $1.5-3.0$ & $\begin{array}{c}\text { cracked roof, partially self-supporting and } \\
\text { bearing, easily passing into a caving state }\end{array}$ & shales, sandy shale, coals \\
\hline $3.0-4.5$ & $\begin{array}{c}\text { self-supporting roof, it goes automatically into a } \\
\text { caving state without sagging into goaf }\end{array}$ & sandstones \\
\hline $4.5-6.0$ & $\begin{array}{c}\text { supporting roof, without roof falls, hardly } \\
\text { passing into caving state, sagging into goaf }\end{array}$ & sandstones \\
\hline$>6.0$ & $\begin{array}{c}\text { strongly compacted roof, very difficult for } \\
\text { passing into caving state }\end{array}$ \\
\hline
\end{tabular}

\section{The goaf permeability}

The coefficient value of gobs permeability is determined based on the value of resistance of rock roof stratification which form the caving. The resistance of roof rock stratification is 
their proper loosening resistance acting against the gravity force, that is natural capability of the rock mass to oppose stratification and caving of roof rock to the heading surface. This resistance determines their tendency to going into caving state. $[3]:$

The resistance of roof rock stratification forming caving is calculating from dependence

$$
R_{r r s}=\frac{\sum_{i=1}^{n} R_{r r i} \cdot m_{i}}{\sum_{i=1}^{n} m_{i}}
$$

where: $R_{r r s}$ is resistance of roof rock stratification $(\mathrm{Pa}), R_{r r i}$ tensile strength of the rock layers $(\mathrm{Pa}), m_{i}$ the thickness of layers $(\mathrm{m})$.

This dependence takes into account an influence of the thickness of particular layers of roof rocks on their tendency to going into caving state.

Resistance of roof rock stratification calculated on the basis of Equation 2, enables to determine permeability coefficient of goaf with caving from Equation 3 [3]:

$$
k(x)=\frac{\mu_{g}}{r_{0}+a x^{2}} \quad \text { for } 0 \leq x \leq 2 / 3 \cdot l
$$

and from dependence [3]:

$$
k(x)=\frac{\mu_{g}}{r_{0}+a\left(\frac{4}{3} l-x\right)^{2}} \quad \text { for } 2 / 3 \cdot l \leq x \leq l
$$

where: $\mu_{g}$ is the coefficient of dynamic viscosity of air $\left(\mathrm{Nsm}^{-2}\right), l$ the total length of the longitudinal longwalls (m), $r_{0}$ we determine from dependence $r_{0}=\frac{\mu}{k_{0}}$ and $a$ we determine from dependence $a=6 \cdot 10{ }^{9} R_{r r s}-1,74$.

Value of coefficient $k_{0}$ we determine from dependence [3]:

$$
k_{0}=\frac{\mu_{g}}{6} \cdot 10^{-10} R_{r r s}^{1,44}
$$

Presented dependences were used during determination of permeability coefficient value of goafs in modeling tests.

\section{Mathematical model of gas flow}

In order to determine particular hazardous zone of endogenous fires in goaf with caving, mathematical model of air stream flowing through porous medium based on below discussed dependences was developed. A turbulent flow of viscous incompressible fluid, was described by the Navier-Stokes system of equations, which together with continuity equation makes a complete system of relationships, allowing to determine pressure and field of flow velocity [16]:

- The continuity equation: 


$$
\frac{\partial \rho}{\partial t}+\frac{\partial(\rho u)}{\partial x}+\frac{\partial(\rho v)}{\partial y}+\frac{\partial(\rho w)}{\partial z}=0
$$

where: $u, v, w$ are directions velocity $(\mathrm{m} / \mathrm{s}), \rho$ is density $\left(\mathrm{kg} / \mathrm{m}^{3}\right)$, and $t$ is time $(\mathrm{s})$.

- The momentum equation:

$$
\frac{\partial}{\partial t}(\rho v)+\nabla \cdot(v v)=-\nabla p+\nabla \tau+\rho g+F
$$

where: $p$ is static pressure $(\mathrm{Pa}), \tau$ is the stress tensor $(\mathrm{Pa}), g$ is the gravitational body force $\left(\mathrm{m} / \mathrm{s}^{2}\right)$ and $F$ is the external body force $(\mathrm{N})$.

The basis of the mathematical description of the transport process of the methane emission to the headings is a mass conservation principle related to this gas. Mathematical model of the transport, being a system of equations of advection-diffusion, which for $i$-th substance it takes the following form:

- The species transport equation

$$
\frac{\partial}{\partial t}\left(\rho Y_{i}\right)+\nabla \cdot\left(\rho v Y_{i}\right)=-\nabla \cdot J_{i}+R_{i}+S_{i}
$$

where: $v$ is velocity $(\mathrm{m} / \mathrm{s}), Y_{i}$ is the local mass fraction of each species, $J_{i}$ is the diffusion flux of species $i\left(\mathrm{~kg} /\left(\mathrm{m}^{2} \mathrm{~s}\right)\right), R_{i}$ is the net rate of production of species $i$ by chemical reaction and $S_{i}$ is the rate of creation by addition from the dispersed phase plus any user-defined sources.

- The mass duffusion in turbulent flows:

$$
J_{i}=-\left(\rho D_{i, m}+\frac{\mu_{t}}{S c_{t}}\right) \nabla Y_{i}
$$

where: $D_{i, m}$ is the mass diffusion coefficient for species $i$ in the mixture $\left(\mathrm{m}^{2} / \mathrm{s}\right), \mu$ is the viscosity $(\mathrm{Pa} \cdot \mathrm{s})$ and $S c_{t}$ is the turbulent Schmidt number, 0.7 .

Airflow through the goaf with caving is a flow through the porous medium. Therefore, to the equation of conservation of momentum, an additional source member Si describing this flow was introduced:

$$
S_{i}=-\left(\frac{\mu_{g}}{k}+C_{2} \frac{1}{2} \rho_{g}|v| v\right)
$$

where: $S i$ is the pressure loss items defined by Darcy's law and $C_{2}$ is the inertial resistance factor.

Flow of air stream through the exploitation longwall and segment of goaf with caving located just behind the sections of mechanical support, in which there was no full caving (determined by so-called caving step) does not correspond to laminar flow (Fig. 1).

Flow of gas streams through the excavations has turbulent character, that is, in which irregular movement of air particles occurs, and its flow parameters undergoes to unpredictable random changes in space and time. In the presented flow analysis the ,,$k-\varepsilon$ standard" turbulence model was applied. This model describes components of the Reynolds turbulent stress tensors according to the Boussinesq hypothesis. 


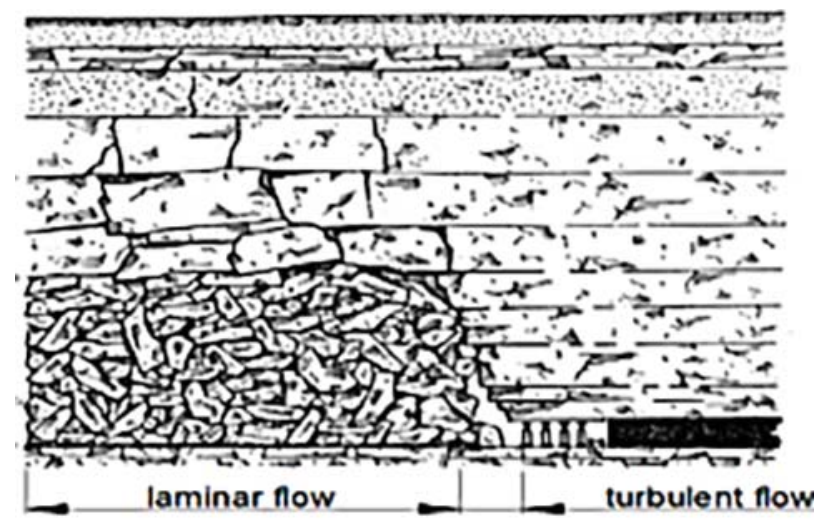

Fig. 1. The character of flow in goaf [1].

In the formula for the components of stress tensor there occur $k$ and $\varepsilon$ quantities. These quantities requires additional two transport equations for single phase flows in a form [15]:

$$
\begin{gathered}
\rho \frac{\partial k}{\partial t}+\frac{\partial}{\partial x_{i}}\left(\rho k u_{i}\right)=\frac{\partial}{\partial x_{j}}\left[\left(\mu+\frac{\mu_{t}}{\sigma_{k}}\right) \frac{\partial k}{\partial x_{j}}\right]+G_{k}+G_{b}-\rho \varepsilon-Y_{M}+S_{k} \\
\rho \frac{\partial \varepsilon}{\partial t}+\frac{\partial}{\partial x i}\left(\rho \varepsilon u_{i}\right)=\frac{\partial}{\partial x_{j}}\left[\left(\mu+\frac{\mu_{t}}{\sigma_{\varepsilon}}\right) \frac{\partial \varepsilon}{\partial x_{j}}\right]+C_{I \varepsilon} \frac{\varepsilon}{k}\left(G_{k}+C_{3 \varepsilon} G_{b}\right)-C_{2 \varepsilon \rho} \frac{\varepsilon^{2}}{k}+S_{\varepsilon}
\end{gathered}
$$

where: $C_{l \varepsilon}, C_{2 \varepsilon}, C_{3 \varepsilon}$ are constans, $\sigma_{k}, \sigma_{\varepsilon}$ turbulent Prandtl numbers for $k$ and $\varepsilon, G_{b}$ the generation of turbulence kinetic energy due to buoyancy, $G_{k}$ the generation of turbulence kinetic energy due to the mean velocity gradients, $Y_{M}$ contribution of the fluctuating dilatation in compressible turbulence to the overall dissipation rate, $S_{k}, S_{\varepsilon}$ user-defined source terms.

\section{Characteristic of investigated system}

In order to perform the analysis, a geometrical model of goaf with caving and exploitation longwall and longwall headings was developed. The vertical extent of airflow in goaf with caving amounted to 3.5 times of the height of exploiting seam $(10.5 \mathrm{~m})$. InFigure 2 there is presented scheme of longwall ventilation with indicated line of air distribution.
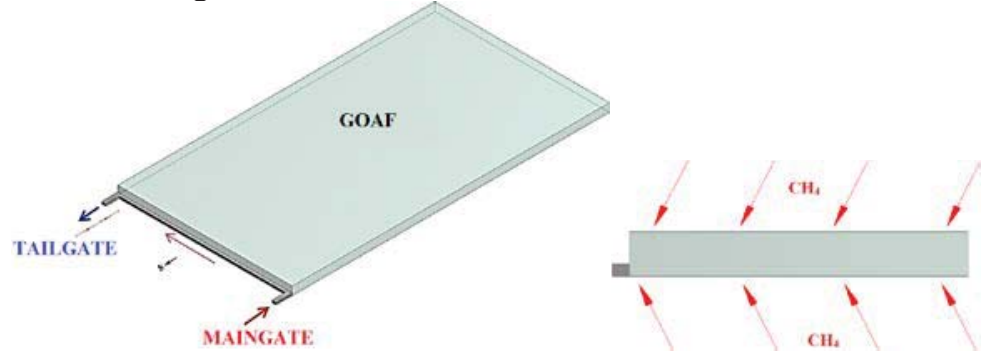

Fig. 2. Geometrical model of investigated system of excavations.

The oxygen part in the air stream supplied to the longwall equals to $21 \%$. Release of methane to the exploitation longwall amounted average to $8,0 \mathrm{~m}^{3} / \mathrm{min}$. The temperature of the air stream supplied to the longwall equals $20^{\circ} \mathrm{C}$. 
Modelling tests order to determination of the impact of roof rock type on location and range of endogenous fires particular hazard zone in goafs were performed for six types of roof rocks forming the goafs. A parameter characterizing type of these rocks was destratification resistance value which decides about goafs permeability. In studies there was assumed that in goafs is located roof rocks with weighted means values appropriately equal to 2, 3, 4, 5, 6 and $7 \mathrm{MPa}$.

\section{Results}

Based on performed calculations distributions of velocity of mixture of air and gases flowing through the goaf with caving and oxygen concentration in this mixture were determined. These values for tested region including goaf with caving with adjacent headings were determined.

In order to clear imaging of obtained results in Figures 3, 4, 5 and 6 there are presented distributions of tested values in parallel planes to slough of exploited seam located at different heights. In Figure 3 there are presented distributions of velocity of air and gases mixture and dangerous velocity because of hazard of endogenous fires in goaf with caving in a distance of $0.5 \mathrm{~m}$ from slough of exploited seam. Whereas, in Figure 4 there is presented oxygen concentration distribution for the same layer. Presented distributions in Figures 3 and 4 were made for remaining rocks in goafs with weighted means values of destratification resistance amounted to $3 \mathrm{MPa}$ and $6 \mathrm{MPa}$.

a

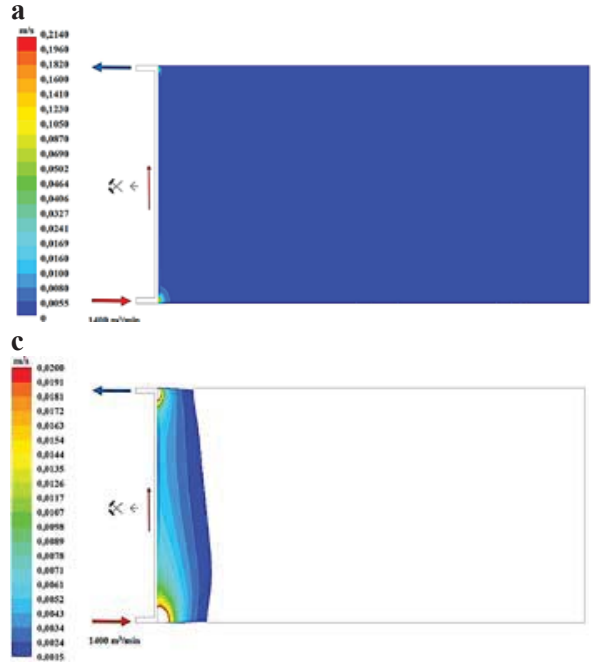

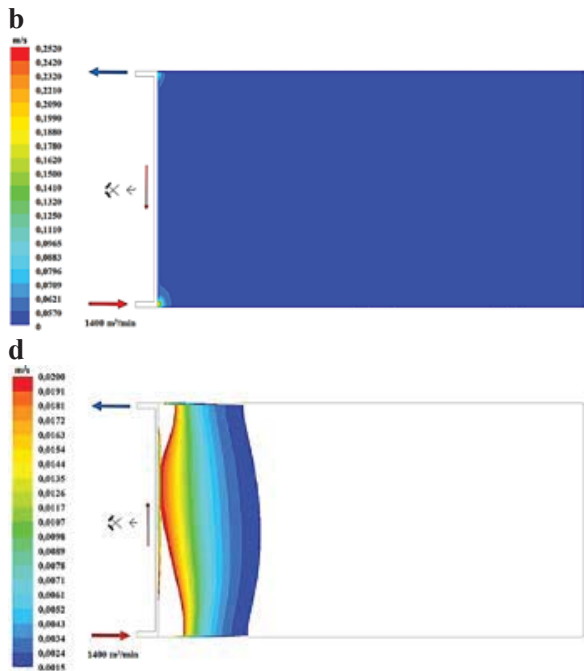

Fig. 3. Distributions of velocity of air and gases mixture (a, b) and dangerous velocity (c, d) because of hazard of endogenous fires in goaf with caving in a distance of $0.5 \mathrm{~m}$ from slough of exploited seam for remaining rocks in goafs with weighted means values of destratification resistance amounted to $3 \mathrm{MPa}(\mathrm{a}, \mathrm{c})$ and $6 \mathrm{MPa}(\mathrm{b}, \mathrm{d})$. 
a)

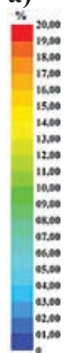

b)

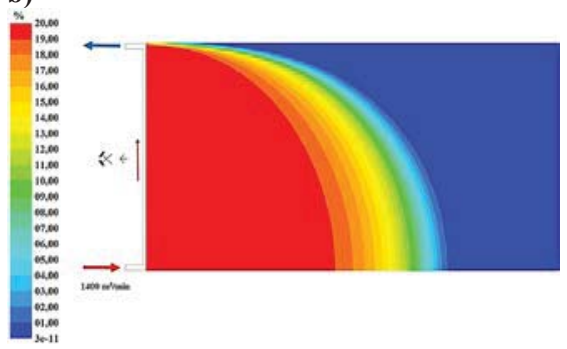

Fig. 4. Oxygen concentration distribution in goaf with caving in a distance of $0.5 \mathrm{~m}$ from slough of exploited seam for remaining rocks in goafs with weighted means values of destratification resistance amounted to $3 \mathrm{MPa}(\mathrm{a})$ and $6 \mathrm{MPa}(\mathrm{b})$.

In Figure 5 and 6 there are presented the same distribution as in Figures 3 and 4 for goaf with caving at a distance $2.0 \mathrm{~m}$ from slough of exploited seam.

a)

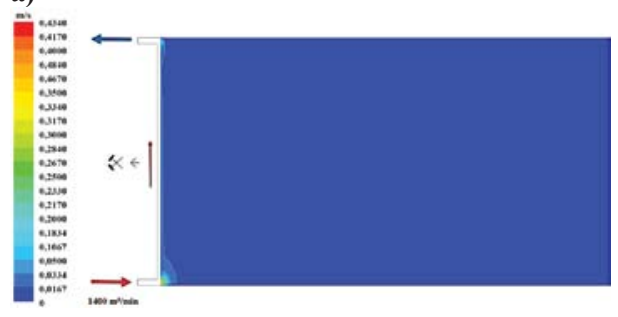

c)

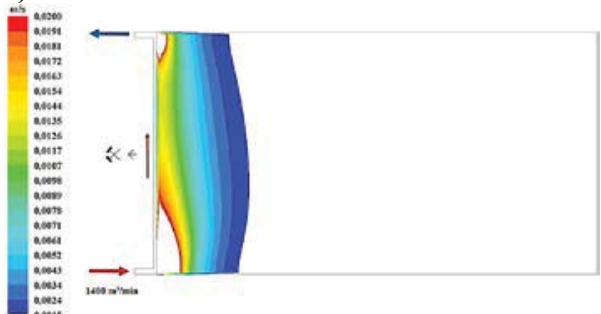

b)

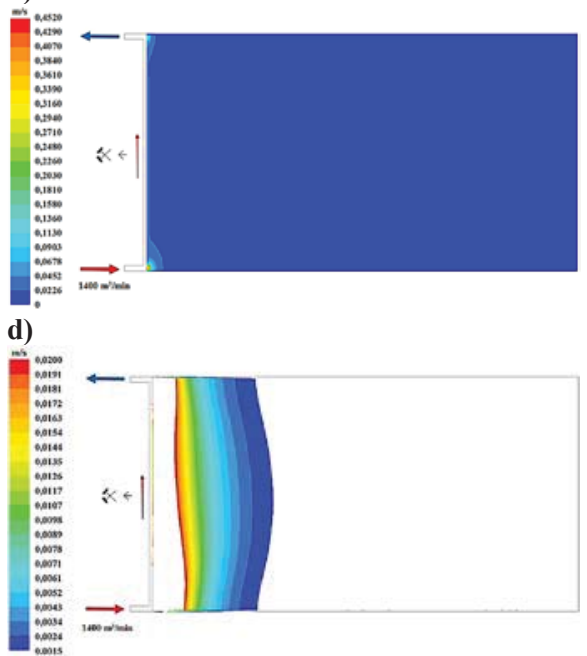

Fig. 5. Distributions of velocity of air and gases mixture ( $a, b)$ and dangerous velocity (c, d) because of hazard of endogenous fires in goaf with caving in a distance of $2.0 \mathrm{~m}$ from slough of exploited seam for remaining rocks in goafs with weighted means values of destratification resistance amounted to $3 \mathrm{MPa}(\mathrm{a}, \mathrm{c})$ and $6 \mathrm{MPa}(\mathrm{b}, \mathrm{d})$. 
a)

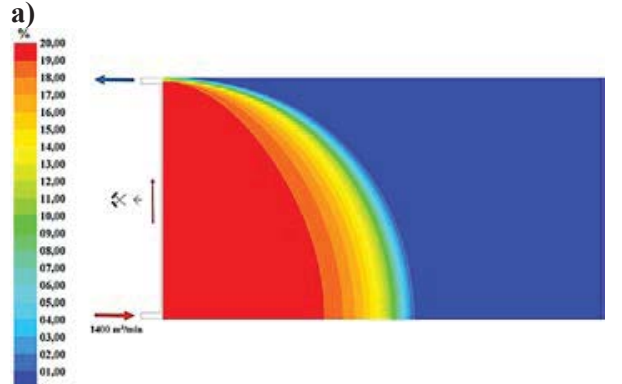

b)

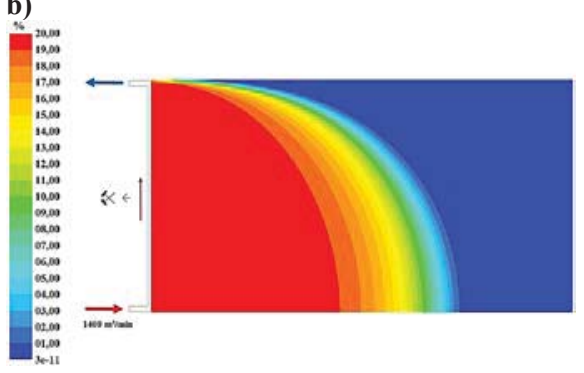

Fig. 6. Oxygen concentration distribution in goaf with caving in a distance of $2.0 \mathrm{~m}$ from slough of exploited seam for remaining rocks in goafs with weighted means values of destratification resistance amounted to $3 \mathrm{MPa}(\mathrm{a})$ and $6 \mathrm{MPa}(\mathrm{b})$.

Based on the obtained results courses of changes in velocity of air flowing through goaf with caving and oxygen concentration in this air depending on the distance from the longwall front for different weighted average values of destratification resistance of roof rocks forming this heap were determined.

In Figures 7 and 8 there are presented comparative characteristics velocity of air flowing though goaf with caving (Fig. 7) and oxygen concentration in this air (Fig. 8) for goafs formed by different types of rocks (characterized by weighted average value of destratification resistance). In these figures, dashed lines indicate dangerous values of air velocity and minimum oxygen concentration due to possibility of occurrence of endogenous fire. These data enable to determine the location and range of zones in which endogenous fire can occur.

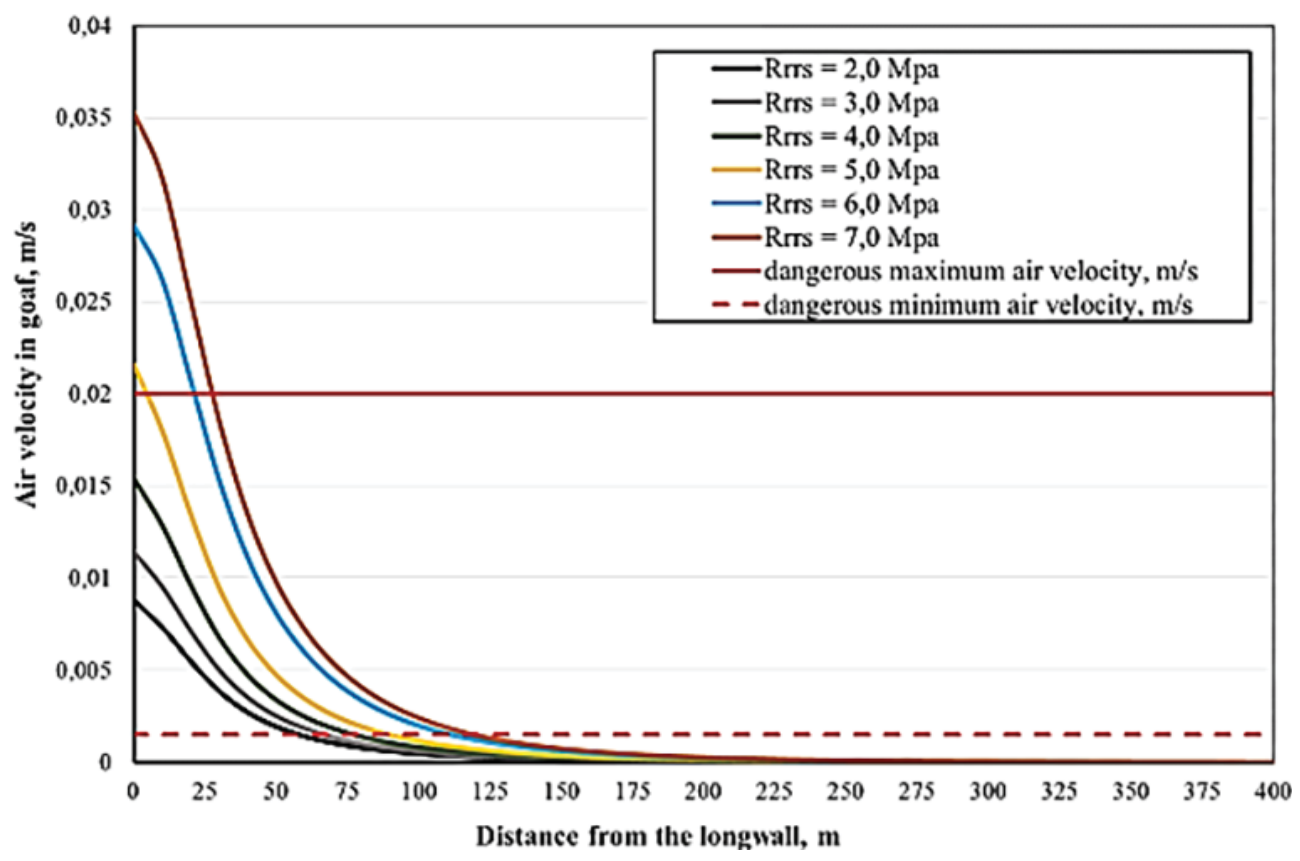

Fig. 7. Comparative characteristics velocity of air flowing though goaf with caving. 


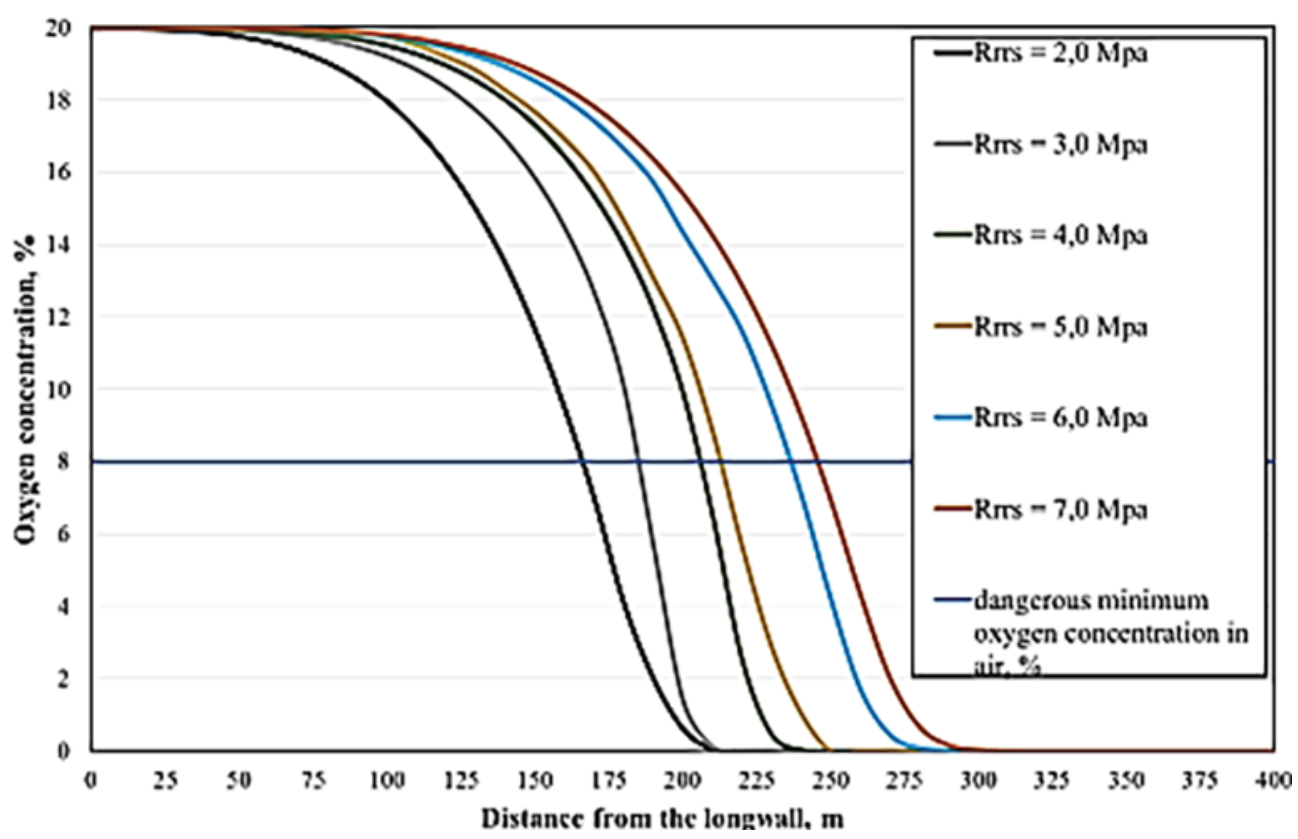

Fig. 8. Comparative characteristics oxygen concentration in air flowing though goaf with caving.

Based on the obtained results location and range of endogenous fires particular hazard zone in goaf with caving depending on weighted mean values of destratification resistance of rocks forming these goafs were determined. Obtained results are shown in Table 2.

Table 2. Location and range of endogenous fires particular hazard zone in goaf with caving depending on weighted mean values of destratification resistance of rocks forming goafs.

\begin{tabular}{|c|c|c|c|}
\hline $\begin{array}{c}\text { The resistance of } \\
\text { roof rock } \\
\text { stratification, } \\
\text { MPa }\end{array}$ & $\begin{array}{c}\text { Critical air velocity } \\
\text { zone, } \mathbf{m}\end{array}$ & $\begin{array}{c}\text { Critical oxygen } \\
\text { concentration zone, } \mathbf{~ m}\end{array}$ & $\begin{array}{c}\text { Particular endogeneous } \\
\text { fires hazard zone, } \mathbf{m}\end{array}$ \\
\hline $\mathbf{2}$ & $0-54.0 \mathrm{~m}$ & $0-154.0 \mathrm{~m}$ & $0-54.0 \mathrm{~m}$ \\
\hline $\mathbf{3}$ & $0-69.0 \mathrm{~m}$ & $0-175.0 \mathrm{~m}$ & $0-69.0 \mathrm{~m}$ \\
\hline $\mathbf{4}$ & $0-84.0 \mathrm{~m}$ & $0-200.0 \mathrm{~m}$ & $0-84.0 \mathrm{~m}$ \\
\hline $\mathbf{5}$ & $11.0-101.0 \mathrm{~m}$ & $0-210.0 \mathrm{~m}$ & $11.0-101.0 \mathrm{~m}$ \\
\hline $\mathbf{6}$ & $21.0-115.0 \mathrm{~m}$ & $0-230.0 \mathrm{~m}$ & $21.0-115.0 \mathrm{~m}$ \\
\hline $\mathbf{7}$ & $25.0 \mathrm{~m}-125.0 \mathrm{~m}$ & $0-242.0 \mathrm{~m}$ & $25.0 \mathrm{~m}-125.0 \mathrm{~m}$ \\
\hline
\end{tabular}

\section{Conclusions}

Model developed and used for flow analysis of mixture of air stream and mining gases through the goaf with caving enabled to determine the distribution of physical and chemical parameters of this mixture for different destratification resistances of rocks forming goaf with caving.

Obtained results enabled to determine of zones particularly endangered by endogenous fires in goafs, in which velocity of airflow equals from $0.0015 \mathrm{~m} / \mathrm{s}$ to $0.02 \mathrm{~m} / \mathrm{s}$, oxygen concentration - min. $8 \%$. Based on that, one can conclude, that location and range of this zone in significantly way depends on a type of roof rocks forming goaf with caving. 
As measure characterizing particular types of rocks forming goafs was assumed destratification resistance of these rocks.

In goaf with caving created from rocks with low value of destratification resistance, the particular hazardous zone of fires forms just behind the front of the longwall, however in goafs created from rocks with high value of this resistance - this zone is distant from the longwall front. This rule regards both to velocity distribution in goafs, and oxygen concentration.

Knowledge of range of this zone has very important practical meaning. It allows to take preventive actions, in order to prevent occurrence of endogenous fire.

Obtained results indicate, that numerical methods can be successfully used for variant analyses of processes connected with ventilation of underground mine headings, including analyses connected with airflow through the goaf, and also in the analyses of emergency states, like initialization of oxidation process in favorable conditions leading to self-heating and self-ignition. Therefore, it can be assumed that simulation methods based on computational fluid dynamics $(C F D)$ could be significant tool in improvement of the occupational safety in the mining.

This article is the result of the research project No. 06/030/BK_17/0024 realized in 2017, financed by MNiSW.

\section{References}

1. A. Lisowski, GIG Works, 2001 (1959)

2. V. Palchik, Env. Geol. 44, 1, DOI: 10.1007/s00254-002-0542-y (2003)

3. J. Szlązak, Arch. Mining Sci. 46 (2001)

4. J. Brodny J. Arch. Mining Sci., 55, 4 (2010)

5. J. Brodny J. Arch. Mining Sci., 56, 1 (2011), DOI: 10.2478/v10267-012-0015-4

6. J. Brodny J. Arch. Mining Sci., 57, 4 (2012)

7. J. Brodny, M. Tutak, 16th International Multidisciplinary Scientific GeoConference. (2016), DOI: 10.5593/SGEM2016/B12/S03.115

8. D. Szurgacz, J. Brodny: 17th International Multidisciplinary Scientific GeoConference. (2017), DOI: doi.org/10.5593/sgem2017/13

9. Y. J. Song, Beijing: The Press of Coal Industry, (2002)

10. K. Cui, J. Shan. Univ. Sci. Techn., 21 (2002)

11. K. Cui, Univ. Sci. Techn., 21 (2002)

12. G. Dai, S. Zhang, M. Tang, AGH J. Min. Geo. 36, 3, (2012)

13. J. Gao, H. Wang, China Saf. Sci. J. 20, 03, (2010)

14. J. Gao, J. Liu and X. Zhang, China Saf. Sci. J., 20, 09, (2010)

15. X. Zhou, Liaoning Technical University (2016).

16. K. K. Veersteg, W. Malalasekera, An Introduction to Computational Fluid Dynamics: The Finite Volume Method (Pearson Education 2007) 